\title{
Do maternal depression and self-esteem moderate and mediate the association between intimate partner violence after childbirth and postpartum suicidal ideation?
}

Md. Jahirul Islam ${ }^{1,2^{*}}$; Lisa Broidy ${ }^{1,3}$; Paul Mazerolle ${ }^{4}$; Kathleen Baird ${ }^{5}$; Nurunnahar Mazumder ${ }^{6}$; and Khondker Mohammad Zobair ${ }^{7}$

${ }^{1}$ School of Criminology and Criminal Justice, Griffith University, 176 Messines Ridge Road, Mt Gravatt Campus, Brisbane, Queensland 4122, Australia.

${ }^{2}$ Ministry of Planning, Bangladesh Planning Commission, Sher-e-Bangla Nagar, Dhaka 1207, Bangladesh

${ }^{3}$ Department of Sociology, 1 University of New Mexico, Albuquerque, NM 87131, United States.

${ }^{4}$ Arts, Education and Law, Griffith University, Mt Gravatt Campus, Brisbane, Queensland 4122, Australia.

${ }^{5}$ School of Nursing and Midwifery, Menzies Health Institute Queensland, Griffith University, Brisbane, QLD, Australia

${ }^{6}$ Department of Law, Jagannath University, Dhaka, Bangladesh

${ }^{7}$ Department of International Business and Asian Studies, Griffith University, Brisbane, Queensland 4111, Australia.

\section{*Corresponding author:}

Name:Dr.Md. Jahirul Islam

Position: Research Fellow

Affiliation and address: School of Criminology and Criminal Justice, Griffith University, 176 Messines Ridge Road, Mt Gravatt, Queensland 4122, Australia

Tel: +61 (0)7 37351202

Email: mdjahirul.islam@griffithuni.edu.au

ORCID: 0000-0001-6409-6724 


\title{
Do maternal depression and self-esteem moderate and mediate the association between intimate partner violence after childbirth and postpartum suicidal ideation?
}

\begin{abstract}
Intimate partner violence (IPV) during the perinatal period is believed to have an adverse effect on maternal mental health. Given the risks of suicide and related public health concerns, the aim of this study is to examine: 1) the association of experiencing physical, psychological, and sexual IPV after childbirth on postpartum suicidal ideation (SI); and 2) whether postpartum depression and self-esteem act to mediate or moderate the relationship between IPV and postpartum SI. A cross-sectional survey was conducted from October 2015 to January 2016 in the Chandpur District of Bangladesh among 426 new mothers, aged 15-49 years, who were in the first six months postpartum. Multivariate logistic regression models were used to examine the association between experiencing IPV and postpartum SI, controlling for a range of other known influences. The prevalence of postpartum SI was $30.8 \%$. Accounting the influence of other confounders, the odds of postpartum SI were significantly higher among women who reported physical IPV victimization (AOR: 2.65; $95 \% \mathrm{CI}=1.36,5.18)$ at any point during the first six months following childbirth as opposed to those who did not. In addition, postpartum depression increased postpartum SI, while high self-esteem significantly reduced reports of SI. Both postpartum depression and maternal selfesteem notably mediate and moderate the effect of physical IPV after childbirth on postpartum SI. The findings illuminate that IPV victimization after childbirth significantly increases the odds of postpartum SI. This study reinforces the need to detect women with a history of IPV who may be at risk for SI, not only to offer them help and support but also to prevent or reduce SI.
\end{abstract}

Keywords: Intimate partner violence; women's mental health; postpartum suicidal ideation; postpartum depression; self-esteem; Bangladesh. 


\section{Introduction}

Pregnancy has been described as a major life-changing event for women, introducing a range of new challenges and adjustments within a family (Bost, Cox, Burchinal, \& Payne, 2002; Deave, Johnson, \& Ingram, 2008). Culturally, for most women and their families; pregnancy, childbirth, and parenting are viewed as a time of great joy and happiness. At the same time, pregnancy and the transition to parenthood can be stressful and anxiety-provoking life events (Bondas \& Eriksson, 2001; Islam, Broidy, Baird, \& Mazerolle, 2017b), and during this period, many women experience perinatal mental health problems, including antenatal depression, postpartum depression, anxiety, posttraumatic stress disorder, and suicidality (Almond, 2009; Fisher et al., 2012). Maternal suicidality is the most severe mental health outcome to manifest in the postpartum period, and is a critical contributor to maternal mortality worldwide (Oates, 2003; Palladino, Singh, Campbell, Flynn, \& Gold, 2011; World Health Organization, 2014). Recent evidence suggests that suicide is the seventh leading cause of maternal mortality within six months postpartum (Cantwell et al., 2011), accounting for $20 \%$ of maternal postpartum deaths (Lindahl, Pearson, \& Colpe, 2005). Such fatal events in the perinatal period are especially notable because they impact the growth and development of the baby, and the function of the family as well as the community as a whole (Gold, Singh, Marcus, \& Palladino, 2012; Muzik, Brier, Menke, Davis, \& Sexton, 2016). Therefore, addressing maternal perinatal mental health problems is crucial to achieving the health and development goals stated in the Sustainable Development Goals (United Nations SecretaryGeneral, 2015; WHO, 2014).

Suicidal ideation (SI) - a terminology used in the medical and psychological arena to characterize an individual's thoughts of suicide — is a precursor to attempted and completed suicide, and common during pregnancy and the postpartum period (Tabb et al., 2017). SI is an important predictor of suicidal behaviour because suicidal thoughts influence suicidal behaviour. This highlights the importance of better understanding the pathways to SI, which can ultimately help better identify pathways to suicide. Although the rate of attempted and 
completed suicides is reportedly lower among pregnant and postpartum women than in the general population of women, it is not trivial; estimated at approximately $4-15 \%$ worldwide (Lindahl, Pearson, \& Colpe, 2005; Newport, Levey, Pennell, Ragan, \& Stowe, 2007) with varying risk factors.

A range of risk factors are associated with suicidal behaviors during the perinatal period. Previous research on suicide demonstrates the influence of a number of individual and contextual factors, including younger age, unmarried status, unemployment, low educational attainment, unintended pregnancy, maternal and infant health status, lack of social support, low self-esteem, experience of childhood abuse, a history of self-harm or suicide attempts, alcohol or drug abuse, and psychiatric disorders (Amiya, Poudel, Poudel-Tandukar, Pandey, \& Jimba, 2014; Czeizel, 2011; Gavin, Tabb, Melville, Guo, \& Katon, 2011; Kim et al., 2014; Mauri, Oppo, Borri, \& Banti, 2012; Pinheiro et al., 2012). While some of these factors are well established, recent evidence introduces that intimate partner violence (IPV) around the time of pregnancy as one of the potential psychosocial risk factors for suicide and SI during the perinatal period (Alhusen, Frohman, \& Purcell, 2015; Gold, Singh, Marcus, \& Palladino, 2012; Gulliver \& Fanslow, 2013; Tabb et al., 2017). Not only do we need more studies validating this finding from a public health perspective, but it is also important to identify malleable factors that mediate or moderate the relationship between experiencing IPV around the time of pregnancy and subsequent postpartum SI. These factors represent potential intervention targets for suicide prevention programs geared towards new mothers experiencing IPV and thus, at risk for SI.

\section{IPV and suicidality around the time of pregnancy: Links and consequences}

IPV is the most frequent form of violence against women, and includes acts of physical, sexual and emotional coercion, as well as controlling behaviors by an intimate partner or husband (World Health Organization, 2013). Regrettably, pregnancy and childbirth do not offer women protection against experiencing IPV (Devries et al., 2010; Islam, Broidy, 
Baird, \& Mazerolle, 2017a; James, Brody, \& Hamilton, 2013). A recent meta-analysis that included studies from the United States as well as from other developed and developing countries, established the prevalence of IPV during pregnancy to be between $4.8 \%$ and $63.4 \%$ (James, Brody, \& Hamilton, 2013). New mothers are also at increased risk for IPV (Adesina, Oyugbo, Oladokun, \& Olubukola, 2011; Woolhouse, Gartland, Hegarty, Donath, \& Brown, 2012) with a prevalence ranging from $2 \%$ to $25 \%$ (Saito, Creedy, Cooke, \& Chaboyer, 2012). Evidence suggests that IPV around the time of pregnancy may escalate in frequency (Martin et al., 2004) and severity (Brownridge et al., 2011). Experiencing IPV in the postpartum period is linked to negative health and parenting practices among mothers, parental stress, infant temperament, and children's cognitive and behavioural problems (Gold, Singh, Marcus, \& Palladino, 2012; Muzik, Brier, Menke, Davis, \& Sexton, 2016; Tsai, Tomlinson, Comulada, \& Rotheram-Borus, 2016). Thus, IPV around the time of pregnancy has been considered as a threat to the health of the women in general, and to women and infants during the postpartum period, in particular (World Health Organization, 2013).

A growing number of studies have revealed a positive relationship between IPV around the time of pregnancy and experiencing perinatal mental health problems (Howard, Oram, Galley, Trevillion, \& Feder, 2013; Islam, Broidy, Baird, \& Mazerolle, 2017b; Leiner, Compton, Houry, \& Kaslow, 2008; Tsai, Tomlinson, Comulada, \& Rotheram-Borus, 2016). More specifically, experiencing IPV, particularly physical IPV can considerably elevate levels of post-traumatic stress disorder and depression, which may contribute to greater risk for SI (Almond, 2009; Pico-Alfonso et al., 2006). Previous studies have revealed a significant association between low self-esteem and SI and suicide attempts in women, as well as depression and hopelessness (Sharaf, Thompson, \& Walsh, 2009). Prior work suggests that low self-esteem intensifies the influence of IPV victimization on mental health and SI, and high self-esteem act as a protective buffer against IPV and SI (Bodnar-Deren, Klipstein, Fersh, Shemesh, \& Howell, 2016; Brausch \& Decker, 2014; Islam, Broidy, Baird, \& 
Mazerolle, 2017b; Islam, Mazerolle, Broidy, \& Baird, 2017; Joiner, 2005; Muzik, Brier, Menke, Davis, \& Sexton, 2016).

Woman's lowered sense of self-esteem creates a feeling of guilt, shame, unworthiness, helplessness, and a negative perception of the self that ultimately increase her frustration, depression, and motivational impairment of problem-solving ability (Deyessa et al., 2009). According to the Joiner's (2005) Interpersonal-Psychological Theory of Suicide, the likelihood of having thoughts of suicide is greater when individuals have the desire to die, and the desire for death is influenced by two perceived psychological states: thwarted belongingness and perceived burdensomeness. The former refers to feelings of social isolation, alienation, and being detached from social networks, whilst the latter refers to the belief that the self is so incompetent (low self-esteem ) that one's existence is a liability for or a burden on others (Ribeiro \& Joiner, 2011). This theory also posits that an individual will act on that desire only if he or she has an 'acquired capability' to do so, and this capability is developed by repeated exposure to painful and provocative events that act to increase pain tolerance and reduce the fear of death (Joiner, 2005; Ribeiro \& Joiner, 2011). Muzik et al. (2016) have stated that exposure to pain and life stressors potentially increases the likelihood of suicide owing to the process of becoming habituated to fearful or painful stimuli, which may diminish death-related apprehension. IPV may be a precursor to developing 'acquired capacity' (Joiner, 2005), and the experience of IPV around the time of pregnancy may heighten stress levels among women, ultimately contributing to postpartum depression (Leung, Martinson, \& Arthur, 2005; Rodríguez et al., 2010; Wang \& Chen, 2006; Wang, Jiang, Jan, \& Chen, 2003). Past research also reveals perinatal SI among women with comorbid depression (Alhusen, Frohman, \& Purcell, 2015; Siegel \& Brandon, 2014; Tabb et al., 2013). Thus, it is important to examine possible interactions among IPV, self-esteem, and postpartum depression on postpartum SI. 
In spite of the fact that research regarding the association between IPV and SI in the general population is advancing, significant gaps still remain. Few studies have examined whether IPV victimization during the transition to parenthood impacts the likelihood of a mother's SI in the postpartum period (Fonseca-Machado, Alves, Haas, Monteiro, \& GomesSponholz, 2015; Rochat, Bland, Tomlinson, \& Stein, 2013). In their recent review of studies assessing the relationship between IPV during pregnancy and maternal mental health disorders in high- and low-income countries, Fonseca-Machado et al. (2014) found no studies investigating the association between IPV and SI. Although previous studies have revealed a possible association between IPV and SI in reproductive-aged women in high-income countries, only a limited number of studies have explored the extent of this association in lowand middle-income countries where approximately $76 \%$ of suicides occur (WHO, 2014). Furthermore, very few studies have accounted for potential confounders, such as self-esteem, which can predict both postpartum depression and IPV victimization in the postpartum period (Islam, Broidy, Baird, \& Mazerolle, 2017b). Therefore, further research is required to better understand the mechanisms involved in the relationship between IPV around the time of pregnancy and postpartum SI.

\section{The current study}

Although South Asia has the highest proportion of maternal deaths for various reasons, very few studies have investigated the association between IPV victimization and SI in this context. In relation to Bangladesh, only one study (see Naved and Akhter (2008)) has explored the association between lifetime IPV victimization and SI among reproductive-aged women, and another study by Gausia et al. (2009) has revealed that IPV victimization before or during pregnancy is a determinant of antenatal SI. However, Gausia et al. (2009)'s study has not considered some key psychosocial factors such as self-esteem, postpartum depression and childhood sexual abuse. We are not aware of any studies from South Asia that have particularly examined the influence of IPV victimization in the postpartum period on 
postpartum SI, despite this being a very critical period for maternal and child health. Given the devastating consequences of postpartum IPV victimization for women and children including difficulties in the maternal-infant bonding, and disturbances in child development (Gold, Singh, Marcus, \& Palladino, 2012; Muzik, Brier, Menke, Davis, \& Sexton, 2016), identifying mediators and moderators in relation to abuse after childbirth and postpartum SI is important in broadening our understanding of SI and for predicting who is at the greatest risk for postpartum SI. To date, it is unclear whether the relation between IPV victimization and SI in the postpartum period is moderated by the same factors that operate in the general population or whether there are other specific moderators that need to be considered for postpartum SI. To further contribute to this important knowledge base, the aim of the current study is to examine: 1) the association of experiencing physical, psychological, and sexual IPV after childbirth with postpartum SI; and 2) whether postpartum depressive symptoms and self-esteem act to mediate or moderate the relationship between IPV and postpartum SI. The current study included self-esteem as a protective factor that may mediate or moderate the relationship between IPV and SI. The study also considered the additional risk for SI that postpartum depression might introduce among women who experience IPV. Taking into account these interaction effects, it is also possible that IPV impacts on SI by reducing women's self-esteem and increasing depression. Particularly considering the high rates of IPV in Bangladesh, examining the connection between IPV victimization around the time of pregnancy and postpartum SI in women of Bangladesh is imperative for early detection and targeted preventative measures to support at-risk women.

\section{Methods}

\section{Setting and participants}

A cross-sectional survey of new mothers was conducted from October 2015 to January 2016 in two upazilas (sub-district) of the Chandpur district of Bangladesh. Women who turned up the Expanded Program on Immunization (EPI) centers to receive immunization 
services for their children were the target population for this study. Eligibility criteria for selecting subjects were married women between 15-49 years of age currently living with their husbands, and who had at least one baby aged six months or younger.

\section{Data collection}

The necessary sample size for this study was estimated to be approximately 426 to obtain a $95 \%$ confidence interval with a $5 \%$ margin of error around a prevalence estimate of $48 \%$. On the basis of previous studies, approximately $48 \%$ of women have experienced physical and/or sexual IPV in Bangladesh (NIPORT et al. 2009). A multistage random sampling procedure was adopted to draw samples. Step by step, two Upazilas (sub-district), 10 Unions (i.e. the administrative unit of an Upazila, 5 Unions per upazila), and 80 EPI or vaccination centers (8 EPI centers per Union) were randomly chosen to implement the survey. EPI centers were selected from a Union-wide EPI center lists collected from the Upazila Health Complex (i.e. regulator of all EIP centers). After choosing Unions randomly, starting with the second EPI center on the list, every third center was selected for the study. Instead of households, EIP centers were chosen because they represent a safe and private setting, and husbands usually do not accompany their wives to these centers (Mohammadhosseini, Sahraean, \& Bahrami, 2010).

Two local female interviewers, with knowledge and experience in anthropology, sociology, and quantitative data collection procedures, were recruited for data collection. The project PI provided a two-day intensive training to interviewers on many important issues, including questionnaire and interview techniques, mechanism of handling sensitive questions, ethical issues, confidentiality, and the safety precautions of both interviewers and respondents in the study. The questionnaire was developed in English but then translated into the local language (i.e. Bengali) by the project PI, who is a native of Bangladesh but also fluent in English. The Bengali version was verified by a bilingual senior academician specializing in the Bengali language and cultural anthropology, and also was very conversant in English. 
Before being used in this study, the questionnaire was piloted with a small number of Bengali-speaking women $(n=15)$ to check the questionnaire for clarity, flow, design, and completion time. After examining the feedback and responses from the pilot study, the format of the questionnaire was revised, a number of sections were reorganized and the wording of some questions was modified. In a safe and private room, interviewers conducted face-to-face structured interviews with eligible women who agreed to participate in the study. Spending one day at each of the selected EPI centers, interviewers approached every mother, and invited each of the eligible women to partake in the study. In total, 453 postpartum mothers were approached to reach the desired sample size, yielding a response rate of $94 \%$.

Each interview required approximately 40-50 minutes. Most women usually come to the EPI centers leaving their household works, even possibly taking leave from their employers. Therefore, each participant received a modest monetary 'thank-you gift' (500 Bangladeshi Taka $(\mathrm{BDT}) \sim 6.50 \mathrm{USD})$ as a partial compensation for their time. Moreover, each respondent was provided with a brochure containing information on community resources on IPV and mental health, including helplines, phone numbers, legal services, which they could access free of charge from government facilities and from NGO's with a nominal charge. Taking safety issues into account, the respondents were cautioned not to take the brochure home if it made them feel unsafe to do so, but rather to leave it with a close family member or friend.

The women were informed that their participation in the study was entirely voluntary and that their participation or non-participation in the study would not affect their healthcare from the EPI centers. Primary counseling services and referrals to local social and psychological services were offered to women who reported IPV victimization. Moreover, women who scored $\geq 10$ on the Edinburgh Postpartum Depression Scale (EPDS) were referred to the nearby District Hospital for further follow-up (Gausia, Fisher, Ali, \& Oosthuizen, 2008). 


\section{Ethical considerations}

Ethics approval was received from the National research ethics committee of Bangladesh Medical Research Council (BMRC/NREC/2013-2016/305) and Griffith University Human Research Ethics Committee (CCJ/41/14/HREC) before conducting the study. The study was also undertaken following the WHO's ethical issues for violence research guidelines (Ellsberg, Heise, Pena, Agurto, \& Winkvist, 2001). In consideration of the sensitive nature and cultural context of the study, interviewers received a verbal informed consent from each respondent by explaining the objectives of the survey, the confidentiality of the interview, and the respondents' rights to withdraw from the study at any time without consequences.

\section{Measures}

\section{Suicidal ideation}

The main outcome of the present study was postpartum SI assessed by using question 10 of the Bangla version of the Edinburgh Postpartum Depression Scale (EPDS) (Cox, Holden, \& Sagovsky, 1987). This suicidal ideation item is widely accepted as an indicator of suicidal, rather than non-suicidal self-harm (Alhusen, Frohman, \& Purcell, 2015; Howard, Flach, Mehay, Sharp, \& Tylee, 2011; Sit et al., 2015). This question asks respondents whether, in the past 7 days, 'the thought of harming herself or suicide has occurred to her'. Response categories range from 0 to 3 ('never' $=0$, 'hardly ever' $=1$, 'sometimes' $=2$, or 'yes, quite often' = 3). Consistent with other studies definition using the EPDS, women who responded with a 2 or 3 on this question were categorized as exhibiting SI (Alhusen, Frohman, \& Purcell, 2015; Howard, Flach, Mehay, Sharp, \& Tylee, 2011; Sit et al., 2015). Postpartum SI was then categorized as: no $=0$ and yes $=1$.

\section{Intimate partner violence}

For the purpose of the study 'intimate partner' refers to the respondent's current spouse. IPV was measured using a modified version of domestic violence questionnaire of the 
WHO Multi-country study which has been validated for use in Bangladesh and other countries (Garcia-Moreno, Jansen, Ellsberg, Heise, \& Watts, 2005). A woman was coded as having experienced physical IPV if she reported to any one of the following seven behaviours: (1) pushing, shaking, or throwing something at her; (2) slapping; (3) twisting her arm or pulling her hair; (4) punching or hitting with a fist or something harmful; (5) kicking or dragging or physically assaulting her; (6) choking or burning; or (7) threatening or attacking with a knife, gun or any other weapon. Each woman was asked if she had experienced any of these indicators of physical IPV after the birth of her last baby. In the present study, the Cronbach's $\alpha$ for this measure was .078.

Sexual IPV was measured if the woman reported having been physically forced to have sexual intercourse; having intercourse out of fear, or being forced to perform other sexual acts that she found degrading or humiliating. For example, one of the sample questions includes "After this childbirth, has your husband physically forced you to have sexual intercourse with him even when you did not want to?" Due to small numbers of items comprising the scale $(n=3)$ in the present study, the Cronbach's alpha for sexual IPV was 0.47 , which is slightly lower when compared to the 0.66 reported in the WHO Multi-country study (Garcia-Moreno, Jansen, Ellsberg, Heise, \& Watts, 2006).

Psychological violence was assessed by at least one positive answer to questions asking whether or not the respondent's husband had insulted her or made her feel bad about herself; humiliated her in front of others; threatened to hurt her or someone close to her; isolated her from friends and family; denied her access to money or other basic resources; or threatened to divorce her. For example, in the present study, the Cronbach's $\alpha$ for psychological IPV was 0.75 .

Binary variables were created as no $(=0)$ and yes $(=1)$ to estimate the prevalence of physical, sexual, and psychological IPV after childbirth. For example, to measure the prevalence of physical IPV, a woman's responses across the seven items on physical IPV 
after childbirth were summed. If she had not experienced any physical IPV, received a 0 , and if she had experienced one or more acts of physical IPV, received a 1. Sexual and psychological IPV were estimated following the same procedure.

\section{Intervening Mechanisms—postpartum depression and self-esteem}

Depression. The EPDS was used to measure postpartum depression, which was hypothesized to mediate or moderate the influence of IPV on SI. This measure has 10 items with four response categories scored from 0 to 3 . However, since item 10 is used to measure SI, we removed it from the depression measure, and used the other 9 items to assess postpartum depression. Postpartum mothers were asked whether they experienced a range of depressive symptoms in the seven days preceding the interview (Islam, Broidy, Baird, \& Mazerolle, 2017b). A higher score refers to higher depressive symptoms. The EPDS cannot confer a diagnosis of depression, however, the Bangla version of the EPDS has shown a sensitivity of $89 \%$ and a specificity of $87 \%$ at the optimum cut-off score of 10 (Gausia, Fisher, Algin, \& Oosthuizen, 2007). Following this, the cut-off score was set at 9 points in the present study to classify women as non-depressed (score $<9=0$ ) and depressed (score $\geq 9=1$ ) because we removed item 10 from the depression measure. In the present study, the Cronbach's $\alpha$ for this scale was 0.90 .

Self-esteem. Women's self-esteem was measured with the Rosenberg self-esteem scale (RSES). The RSES is a 10-item scale that assesses self-esteem by measuring both positive and negative feelings about the self (Rosenberg, 1965). All items are answered using a 4-point Likert scale format $(1=$ strongly disagree, $2=$ disagree, $3=$ agree, and $4=$ strongly agree). After reverse scoring for some items, total score ranges from 0-30. Higher scores refer to higher self-esteem. The Bangla version of RSES was validated in Bangladesh (Islam, Broidy, Baird, \& Mazerolle, 2017b; Uddin, Islam, \& Asaduzzaman, 2012). No predetermined cut-points for low self-esteem exist (Isomaa, Vaananen, Forojd, Kaltiala-Heino, \& Marttunen, 
2013). However, the cut-off score was set for this analysis at 15 points to classify women with low self-esteem (score $<15=0$ ) versus high self-esteem (score $\geq 15=1$ ) following the guidelines of some organizations (The Participation and Quality of Life Tool-Kit, 2016; W.W. Norton and Company, 2016). In this study, the internal consistency for this scale was very good (Cronbach's $\alpha=.84)$.

\section{Sociodemographic, reproductive, and psychosocial characteristics}

Measures of sociodemographic, reproductive, and psychosocial variables were included in the analyses as control variables. Theoretically and empirically associated sociodemographic variables (Gelaye, Kajeepeta, \& Williams, 2016) were included in this study to control for their influence on the postpartum SI. The maternal age during the last pregnancy was grouped into three categories, roughly representative of adolescence $(14-18$ years $=0)$, young adulthood $(19-24$ years $=1)$, and adulthood $(25$ years and over $=2)$. The maternal education level was classified with regard to the formal education system of Bangladesh: no education $(0$ year $s=0)$, primary $(1-5$ years $=1)$, and secondary and higher $(6$ years or more=2). Family monthly income was categorized according to the national average of Bangladesh $(8500 \mathrm{BDT} \sim 109 \mathrm{USD})$ as $\leq 8500 \mathrm{BDT}(=0)$ versus $>8500 \mathrm{BDT}(=1)$.

Theoretically and empirically associated reproductive characteristics (Gausia, Fisher, Ali, \& Oosthuizen, 2009; Gavin, Tabb, Melville, Guo, \& Katon, 2011; Mauri, Oppo, Borri, \& Banti, 2012; Pinheiro et al., 2012) such as pregnancy intention (unintended $=0$, intended $=1$ ), parity $($ primiparous $=0$, multiparous $=1)$, complications during childbirth $($ no $=0$, yes $=1)$, maternal general health status $(\operatorname{good}=0$, fair $=1, \mathrm{bad}=2)$, and husband's preference for a son while delivered a daughter (no $=0$, yes $=1)$ were included in the study.

Childhood sexual abuse. A woman was coded as having experienced childhood sexual abuse if she had ever been forced to have sex, kissed, or forced to undress or perform sexual acts against her will before 15 years of age. Respondents answered either no (0) or yes (1). 
Social support. We controlled for social support given its protective impacts on mental health in general and SI in particular (Brausch \& Decker, 2014; da Cunha Coelho et al., 2014; Peltzer, 2015; Pinheiro et al., 2012). Chan et al.(2011) adopted a 10-item social support scale from the Family Needs Screener [a short version of personal and relationship profile prepared by Straus and associates (Kantor \& Straus, 1999)]. Women were asked to respond using four response categories $(1=$ strongly disagree, $2=$ disagree, $3=$ agree, and $4=$ strongly agree) to the 10 statements. These items have been described in detail elsewhere (Islam, Baird, Mazerolle, \& Broidy, 2017). The total score was derived by summing all items, with higher scores indicating greater social support (instrument range: 10-40). For the analysis, total scores were categorized into low, medium, and high levels of social support by tertiles. More specifically, women with total scores in the bottom third tertile were classified as having low social support $(=0)$, those in the middle third as evidencing medium social support $(=1)$, and those in the top third as showing high social support $(=2)$. The items showed good internal consistency in the present study (Cronbach's $\alpha=.90$ ).

\section{Statistical analyses}

Coding and analyzing the data was performed using SPSS version 22.0 for Windows (SPSS Inc., Chicago, IL, USA). Descriptive statistics were calculated for mother's postpartum SI, IPV experiences as well as other control variables. Analysis of this study proceeded in two stages. First, a series of cross-tabulations were conducted to assess the bivariate associations between postpartum SI and the relevant covariates and controls, and report chi-squares as our measure of significance. A two-tail $p$-value of $<.05$ was set to refer the level of statistical significance for all analyses. A series of multivariate logistic regression models were then estimated to assess the strength of any association between each of the IPV variables and postpartum SI, controlling for other known variables. The multicollinearity of the variables was checked by inspecting the variance inflation factors (VIF's $<2.5$ ), but there was no evidence that this was a problem. To evaluate the influence of different forms of IPV on the 
odds of postpartum SI, four adjusted multivariate logistic regression models were estimatedone for each type of IPV to determine the independent effect of different types of IPV on postpartum SI (Table 2, Models 1-3), and one model for all types of IPV together to evaluate the influence of each type of IPV, controlling for the other (Table 2, Model 4).

We performed another set of multivariate analyses to assess whether women's postpartum depressive symptoms and low self-esteem mediate or moderate any relationship between IPV after childbirth and postpartum SI. In the first instance (mediation), we introduced postpartum depression and self-esteem into the model to see if any association of IPV with postpartum SI attenuated once postpartum depression and self-esteem were taken into account (Table 2, Model 5). In the second instance (moderation), we included an interaction term for postpartum depressive symptoms and IPV after childbirth, and assessed whether experiencing postpartum depressive symptoms exaggerates the impact of IPV on postpartum SI (Fig. 2). Additionally, we included an interaction term for self-esteem and IPV, and examined whether the interaction of self-esteem and IPV after childbirth was such that the effect on IPV is greater for women with less self-esteem (Fig. 3). For assessing the interaction effect, we only considered physical IPV because one of our recent studies (XXX) have revealed that only physical IPV has a direct effect on postpartum depression and other studies have demonstrated that high self-esteem act as a protective buffer against physical IPV (Islam, Mazerolle, Broidy, \& Baird, 2017; Loft Abadi, Ghazinour, Nojomi, \& Richter, 2012).

\section{Results}

\section{Profile of the respondents}

Table 1 displays the socioeconomic and demographic characteristics of the women in our sample. Just less than half of the women (43.9\%) were 19-24 years old during their most recent pregnancy, approximately $8.2 \%$ of women had no formal education, and about $38.3 \%$ women had an average monthly income less than or equal to the national average. One-fourth 
of the women's most recent pregnancies were unintended, about $16.2 \%$ of women had complications during childbirth, and $35.2 \%$ of women reported postpartum depressive symptoms. Furthermore, approximately $41 \%$ of women had only one child ${ }^{1}$, and $20.4 \%$ of women had husbands whose preference was for a son, while the mother delivered a daughter.

Table 1 Sociodemographic and other characteristics of women, and bivariate association of these characteristics with postpartum SI $(N=426)$

\begin{tabular}{|c|c|c|c|}
\hline \multirow{2}{*}{ Characteristics } & \multirow{2}{*}{$n(\%)$} & \multicolumn{2}{|c|}{ Suicidal ideation } \\
\hline & & $\%$ & $p$-value \\
\hline \multicolumn{4}{|l|}{ Socio-demographic characteristics } \\
\hline \multicolumn{4}{|l|}{ Maternal age during pregnancy } \\
\hline $14-18$ & $106(24.9)$ & 31.1 & .20 \\
\hline $19-24$ & $187(43.9)$ & 26.7 & \\
\hline$\geq 25$ & $133(31.2)$ & 36.1 & \\
\hline \multicolumn{4}{|l|}{ Maternal education } \\
\hline No formal education & $35(8.2)$ & 51.4 & $<.001$ \\
\hline Primary education & $104(24.4)$ & 51.0 & \\
\hline Secondary and higher education & $287(67.4)$ & 20.9 & \\
\hline \multicolumn{4}{|c|}{ Family monthly income, Bangladeshi Taka } \\
\hline$\leq 8500$ & $163(38.3)$ & 46.0 & $<.001$ \\
\hline$>8500$ & $263(61.7)$ & 21.3 & \\
\hline \multicolumn{4}{|l|}{ Reproductive characteristics } \\
\hline \multicolumn{4}{|l|}{ Parity } \\
\hline Primiparous & $175(41.1)$ & 28.6 & .42 \\
\hline Multiparous & $251(58.9)$ & 32.3 & \\
\hline \multicolumn{4}{|l|}{ Pregnancy intention ${ }^{\ddagger}$} \\
\hline Unintended & $107(25.1)$ & 38.3 & .05 \\
\hline Intended & $319(74.9)$ & 28.2 & \\
\hline \multicolumn{4}{|l|}{ Complications during childbirth } \\
\hline No & $357(83.8)$ & 31.1 & .73 \\
\hline Yes & $69(16.2)$ & 29.0 & \\
\hline \multicolumn{4}{|l|}{ Maternal health status } \\
\hline Good & $247(58.0)$ & 25.9 & .03 \\
\hline Fair & $135(31.7)$ & 35.6 & \\
\hline $\mathrm{Bad}$ & $44(10.3)$ & 43.2 & \\
\hline \multicolumn{4}{|c|}{ Husband preferred a son while delivered a daughter } \\
\hline No & $339(79.6)$ & 27.7 & .01 \\
\hline Yes & $87(20.4)$ & 42.5 & \\
\hline \multicolumn{4}{|l|}{ Psychosocial characteristics } \\
\hline \multicolumn{4}{|l|}{ Childhood sexual abuse } \\
\hline No & $364(85.4)$ & 28.0 & \\
\hline Yes & $62(14.6)$ & 46.8 & .003 \\
\hline \multicolumn{4}{|l|}{ Postpartum depressive symptoms } \\
\hline Non-depressed & $276(64.8)$ & 9.4 & $<.001$ \\
\hline Depressed & $150(35.2)$ & 70.0 & \\
\hline \multicolumn{4}{|l|}{ Social support } \\
\hline Low & $128(30.0)$ & 58.3 & $<.001$ \\
\hline
\end{tabular}




\begin{tabular}{lccc}
\hline \multicolumn{1}{c}{ Characteristics } & $\boldsymbol{n}(\boldsymbol{\%})$ & \multicolumn{2}{c}{ Suicidal ideation } \\
\cline { 4 - 5 } & & $\%$ & $p$-value \\
\hline Medium & $158(37.1)$ & 29.6 & \\
High & $140(32.9)$ & 1.5 & \\
Self-esteem & & & \\
$\quad$ Low & $249(58.5)$ & 51.0 & $<.001$ \\
High & $177(41.5)$ & 2.3 & \\
Physical IPV after childbirth & & & \\
No & $289(67.8)$ & 12.8 & $<.001$ \\
Yes & $137(32.2)$ & 68.6 & \\
Sexual IPV after childbirth & & & \\
No & $360(84.5)$ & 27.2 & $<.001$ \\
Yes & $66(15.5)$ & 50.0 & \\
Psychological IPV after childbirth & & & \\
No & $167(39.2)$ & 3.6 & $<.001$ \\
Yes & $259(60.8)$ & 48.3 & \\
\hline & Total & 30.8 & \\
\hline
\end{tabular}

¥ Intended: live birth wanted at the time of conception or unintended: live birth wanted later or not at all.

\section{Prevalence of IPV and postpartum SI}

Overall, approximately $64 \%$ of women in this sample reported any IPV victimization during the postpartum period (see Table 1). More specifically, the prevalence of physical IPV after childbirth was $32.2 \%$. The most common form of IPV reported by the women was psychological IPV after childbirth (60.8\%), and the least common form was sexual IPV (15.5\%).

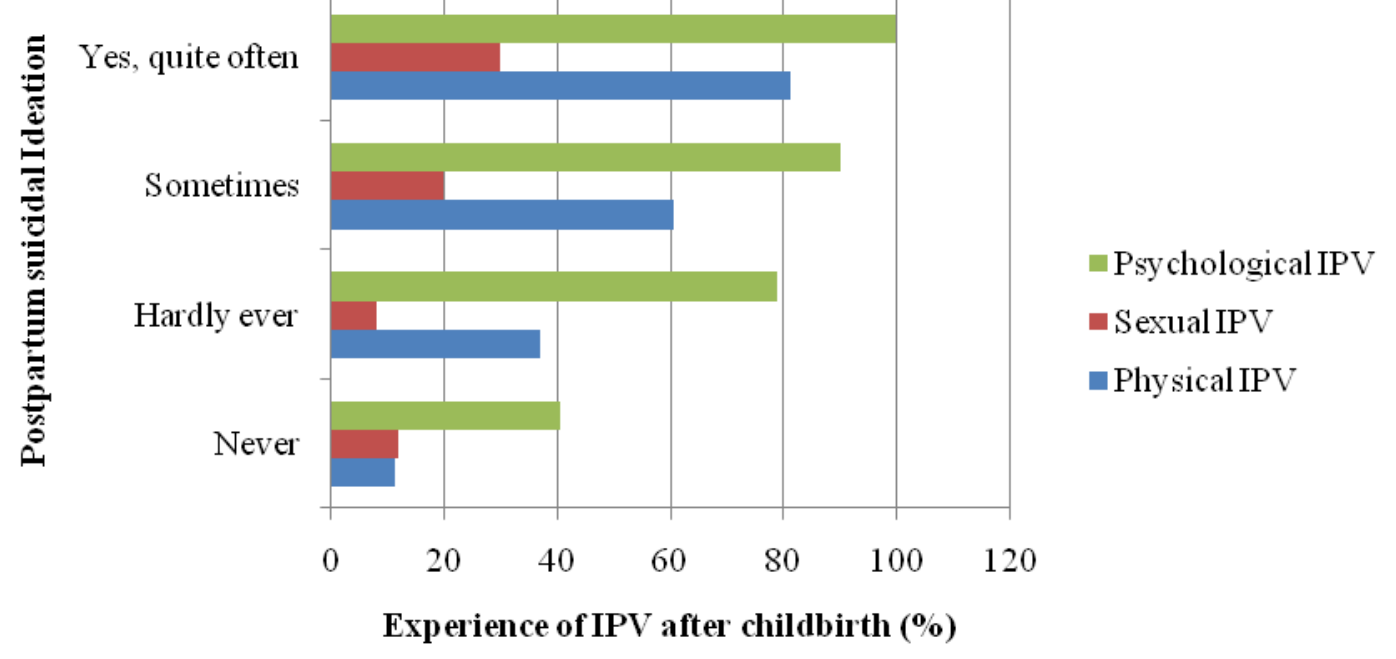

Fig.1 Postpartum SI and experience of IPV after childbirth 
Out of 426 respondents, 131 indicated that either "quite often" or "sometimes" had thoughts of harming themselves, which translates into $30.8 \%$ prevalence for SI among these post-partum women. As shown in Fig. 1, those who reported SI symptoms were also more likely to report psychological, physical and sexual IPV after childbirth. It is notable that amongst respondents reporting suicidal ideation "quite often", all of them had also experienced psychological IPV.

\section{IPV and postpartum SI: Bivariate associations}

The results of the bivariate analysis illustrated several significant differences in the likelihood of postpartum SI as a function of sociodemographic, reproductive, and psychosocial characteristics (see Table 1). As expected, physical, sexual, and psychological IPV after childbirth were all significantly linked with postpartum SI among the women in this sample. On an average, $68.6 \%$ of women who experienced physical IPV, $50 \%$ of those who experienced sexual IPV, and $48.3 \%$ of women who experienced psychological IPV after childbirth also reported postpartum SI. Bivariate outcomes also underscore the significance of controlling for other covariates that influence women's likelihood of postpartum SI. We directly test these relationships with multivariate models that are detailed below.

\section{IPV and postpartum SI: Multivariate analysis}

Results reported in Table 2 demonstrate outcomes of multivariate models investigating the impacts of IPV on postpartum SI controlling for a number of covariates included in the survey. Each type of IPV after childbirth was examined separately (Table 2, Models 1-3), then jointly (Table 2, Model 4). Analyses then assessed whether the inclusion of postpartum depression and self-esteem mediated any effects of IPV on postpartum SI (Table 2, Models 5). Given overlap across types of IPV, the combined model allows us to evaluate whether the impact of any specific type of IPV holds controlling for other forms of IPV. Models 1-3 demonstrate that physical and psychological IPV following childbirth significantly impacted postpartum SI, and only physical IPV remained significant in the full model (Table 2, Model 5). After childbirth, women with no physical IPV were 2.78 -fold more likely to have 
postpartum SI than women who were not exposed to such violence. Childhood sexual abuse was not significant in the full model (Model 5). In addition, sexual IPV did not significantly impact the odds of postpartum SI, this may be an artefact of the low rate of postpartum sexual IPV compared to the other two forms of IPV we examined.

We also examined whether the relationship between IPV and postpartum SI was partially mediated by postpartum depression and self-esteem. Results in Model 5 indicate that postpartum depression increased the odds of postpartum SI, and high self-esteem significantly reduced the odds of postpartum SI. More notably, the inclusion of postpartum depression and self-esteem in the model significantly reduced the impact of physical IPV after childbirth on postpartum SI. This indicates that part of the reason postpartum IPV is correlated with SI is due to its influence on depression and self-esteem among postpartum women. 
Table 2: AORs for the association between IPV victimization after childbirth and the postpartum SI $(N=426)$

\begin{tabular}{|c|c|c|c|c|c|}
\hline \multirow{2}{*}{ Independent variable } & \multicolumn{4}{|c|}{ Postpartum SI, AOR (95\% CI) } & \multirow[b]{2}{*}{ Model 5 (Full } \\
\hline & Model 1 & Model 2 & Model 3 & Model 4 & \\
\hline No & 1.00 & - & - & 1.00 & 1.00 \\
\hline \multicolumn{6}{|l|}{ Sexual IPV after childbirth } \\
\hline No & - & 1.00 & - & 1.00 & 1.00 \\
\hline Yes & - & $1.76(0.93-3.33)$ & - & $1.02(0.51-2.03)$ & $1.18(0.55-2.54)$ \\
\hline Yes & - & - & $8.84(3.48-22.48)^{*}$ & $4.88(1.83-13.00)^{* *}$ & $3.10(0.99-9.65)$ \\
\hline \multicolumn{6}{|l|}{ Childhood sexual abuse } \\
\hline No & & & & 1.00 & 1.00 \\
\hline Yes & & & & $1.24(0.62-2.48)$ & $1.36(0.63-2.94)$ \\
\hline \multicolumn{6}{|l|}{ Postpartum depression } \\
\hline Non-depressed & - & - & - & - & 1.00 \\
\hline$-2 \log$ likelihood & 326.23 & 373.19 & 345.21 & 313.97 & 237.25 \\
\hline$R^{2}($ Cox \& Snell $)$ & .37 & .30 & .35 & .39 & .49 \\
\hline$R^{2}$ (Negelkerke) & .53 & .43 & .49 & .55 & .69 \\
\hline Model $\chi^{2}$ & $199.53^{*}$ & $152.58^{*}$ & $180.56^{*}$ & $211.79^{*}$ & $288.52^{*}$ \\
\hline Overall model prediction rate & $84 \%$ & $76 \%$ & $80 \%$ & $84 \%$ & $88 \%$ \\
\hline
\end{tabular}

Note: AOR = Adjusted Odds Ratio; $\mathrm{CI}=$ Confidence interval; IPV= Intimate partner violence.

Here ${ }^{*} p<0.001 ; * * p<0.01 ; * * * p<0.05$

Model 1: Influence of physical IPV after childbirth adjusted for maternal age during pregnancy, maternal education, family income, parity, pregnancy intention, complications during childbirth, maternal health status, husband preferred a son while delivered a daughter, and social support.

Model 2: Influence of sexual IPV after childbirth adjusted for the above variables. 
Model 3: Influence of psychological IPV after childbirth adjusted for the above variables.

Model 4: Influence of all types of IPV after childbirth and childhood sexual abuse adjusted for the above variables.

Model 5: Influence of all types of IPV after childbirth and childhood sexual abuse adjusted for the above variables including postpartum depression and self-esteem. 
Fig. 2 Interaction of physical IPV AND postpartum depression on postpartum SI

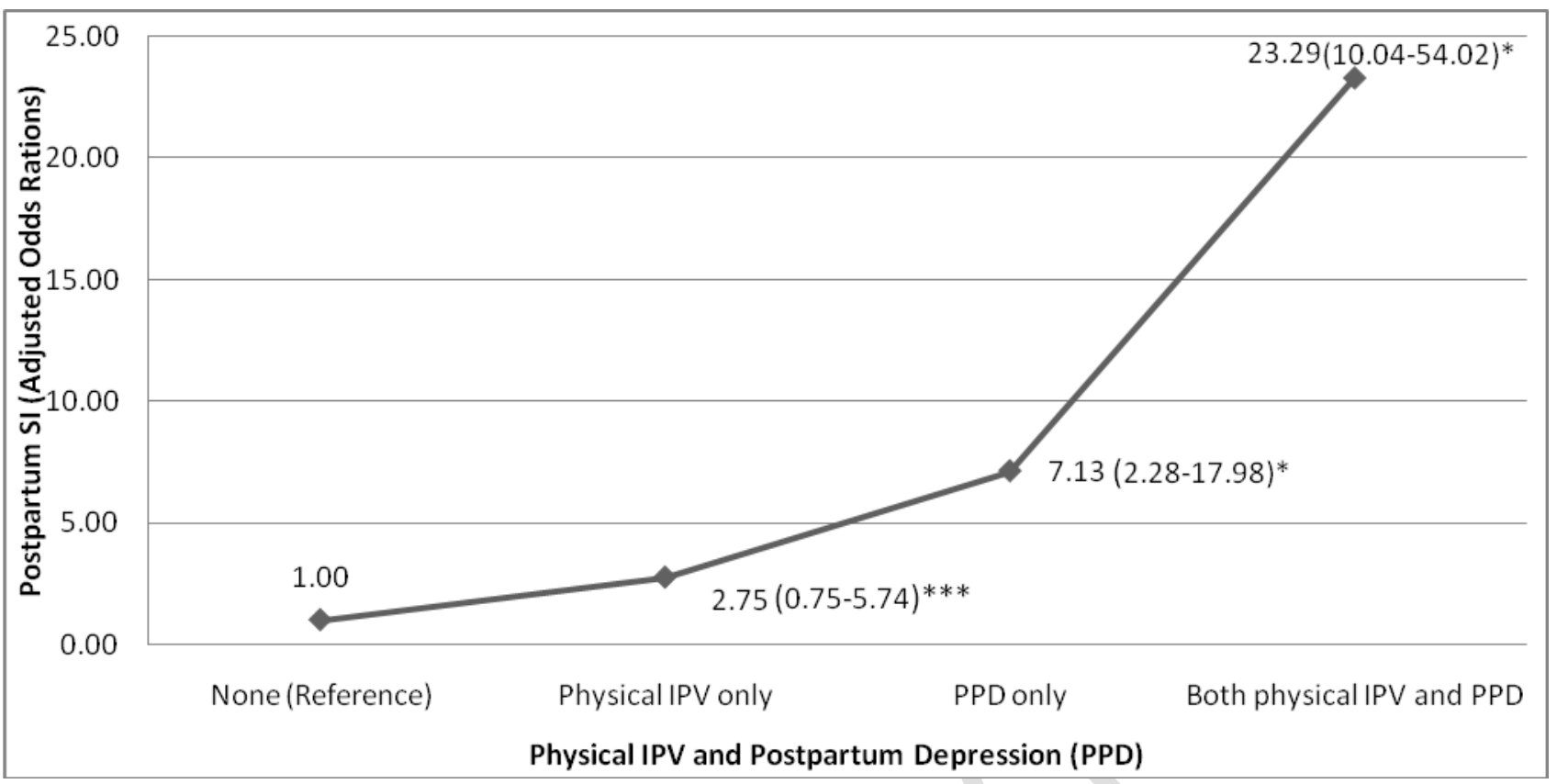

Note: The model adjusted for sexual and psychological IPV after childbirth, age during pregnancy, education, family income, parity, pregnancy intention, complications during childbirth, maternal health status, husband preferred a son while delivered a daughter, social support, self-esteem, and childhood sexual abuse.

Here, ${ }^{*} p<0.001, * * * p<0.05$

Fig.3 Interaction of physical IPV after childbirth AND self-esteem on postpartum SI

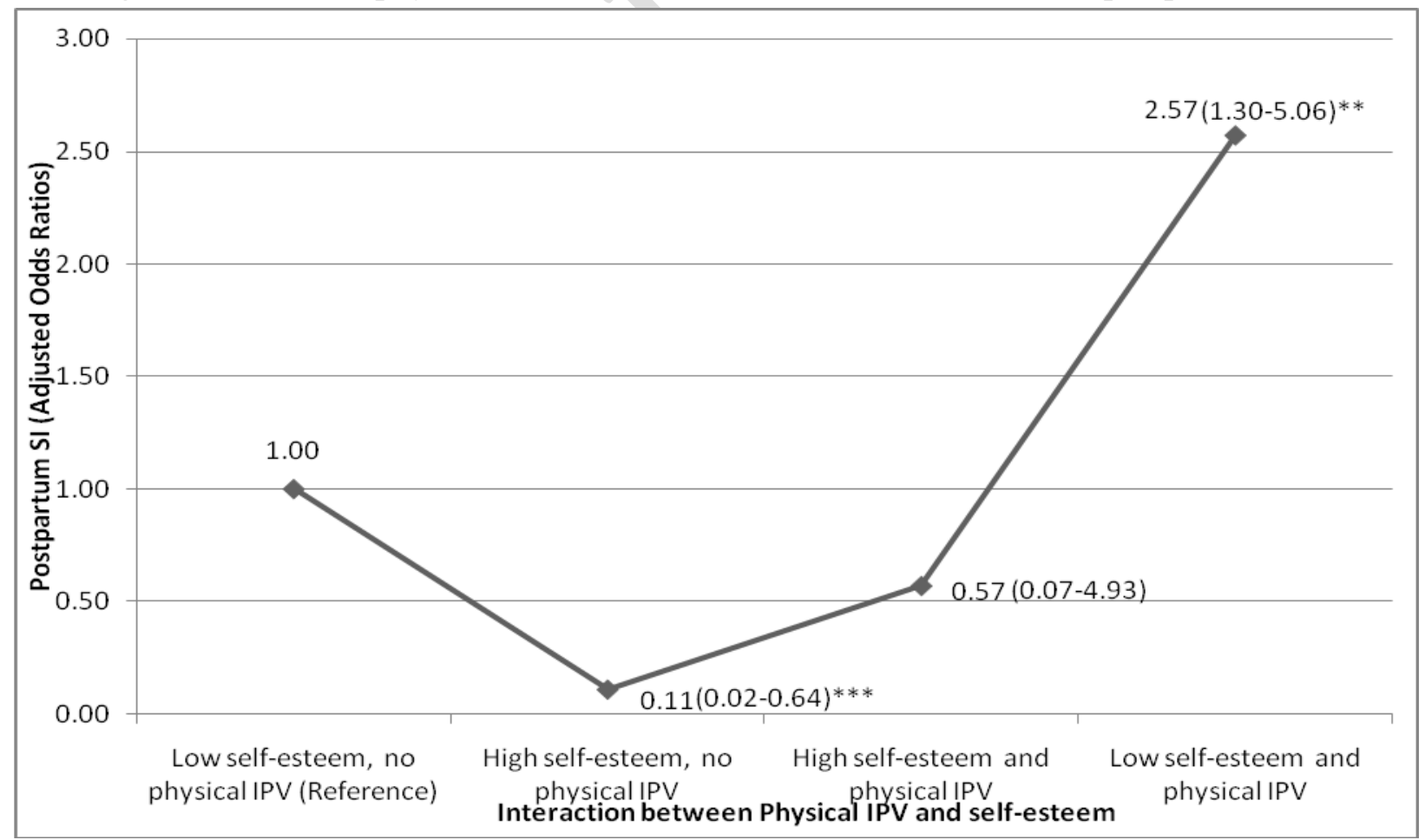

Note: The model adjusted for sexual and psychological IPV after childbirth, age during pregnancy, education, family income, parity, pregnancy intention, complications during childbirth, maternal health status, husband preferred a son while delivered a daughter, social support, childhood sexual abuse and postpartum depression.

Here, $* * p<0.01 ; * * * p<0.05$ 
Results from Fig. 2 and 3 illustrate the interaction of physical IPV with postpartum depression and self-esteem. The multivariate logistic regression model revealed that the interaction effect between physical IPV and postpartum depression on postpartum SI was very high (AOR: 23.29; 95\% CI $=10.04,54.02)$ compared with mothers who experienced neither physical IPV nor postpartum depression (Fig. 2). In addition, the interaction between experiencing physical IPV and low self-esteem had a significant effect on the postpartum SI (AOR: $2.57 ; 95 \% \mathrm{CI}=1.30,5.06)$ compared with no physical IPV and low self-esteem (Fig. 3).

\section{Discussion}

In this study, we examined the association between experiencing IPV after childbirth and postpartum SI in a sample of new mothers in Bangladesh. Even though a number of studies have explored the influence of experiencing IPV on women's SI in general (McLaughlin, O'Carroll, \& O'Connor, 2012), our study contributes to the literature by demonstrating independent effects of experiencing physical, sexual, and psychological IPV after childbirth on SI in the postpartum period. Findings from this study signify that IPV after childbirth and postpartum SI are clearly two notable issues in Bangladesh. Almost one-third of women in this sample reported postpartum SI. Moreover, the risk for postpartum SI is significantly higher among women who experienced physical IPV after childbirth.

In this study, the prevalence of postpartum SI was $30.8 \%$, which is slightly higher than the $28.8 \%$ prevalence in Zimbabwe (Shamu, Zarowsky, Roelens, Temmerman, \& Abrahams, 2016), and lower than the $37 \%$ prevalence in the USA (Muzik, Brier, Menke, Davis, \& Sexton, 2016), and the 41.2\% prevalence in South Africa (Peltzer, 2015). A literature review including studies from the United States as well as other developed and developing countries reported that $4-15 \%$ women had expressed SI or self-harming thoughts during pregnancy and the postpartum period (Lindahl, Pearson, \& Colpe, 2005). Our postpartum SI prevalence estimate is much higher than the reported prevalence of $11-14 \%$ during lifetime (Naved \& 
Akhtar, 2008), and 14\% during pregnancy among ever-married women in Bangladesh (Gausia, Fisher, Ali, \& Oosthuizen, 2009). The variation in the prevalence estimate across studies is possibly due to the difference in instruments and method used (cross-sectional or longitudinal), varying sample size (mostly small), and differing timeframes for assessment. As participants in our study were not at the same stage in their postpartum period (1-6 months), their experience of postpartum depression and SI may be different, which might be a reason for the variation in prevalence.

Our primary aim in this study was to assess the association between maternal IPV victimization after childbirth and postpartum SI. This study joins a growing but limited body of evidence on the relationship between IPV experiences around the time of pregnancy and postpartum SI (Alhusen, Frohman, \& Purcell, 2015; Onah, Field, Bantjes, \& Honikman, 2017; Palladino, Singh, Campbell, Flynn, \& Gold, 2011; Pinheiro et al., 2012; Rodriguez, Cook, Peltzer, \& Jones, 2017; Shamu, Zarowsky, Roelens, Temmerman, \& Abrahams, 2016; Sit et al., 2015; Tabb et al., 2017). This study reveals that experiencing physical IPV following childbirth increases the likelihood of postpartum SI among the new mothers, even after controlling for key covariates. This result comports with limited studies associating physical IPV to perinatal SI (Pinheiro et al., 2012; Rodriguez, Cook, Peltzer, \& Jones, 2017; Shamu, Zarowsky, Roelens, Temmerman, \& Abrahams, 2016).

In this study, we were particularly interested in how postpartum depression (a comorbid risk factor) and self-esteem (a potential protective factor) might both mediate and moderate the effects of postpartum IPV on SI during the postpartum period. Prior work has found that experiencing IPV, in particular, physical IPV can significantly raise levels of stress and depressive symptoms (Almond, 2009; Pico-Alfonso et al., 2006), which might explain how IPV translates into elevated risk for SI. Further, self-esteem is known to buffer the effects of victimization on mental health symptoms and SI (Bodnar-Deren, Klipstein, Fersh, Shemesh, \& Howell, 2016; Brausch \& Decker, 2014; Joiner, 2005; Muzik, Brier, Menke, 
Davis, \& Sexton, 2016). Our findings suggest that depression and self-esteem are important mechanisms that help account for the relationship between IPV victimization and postpartum SI. Mediation models indicate that a significant portion of the relationship between IPV and SI operates through depression and self-esteem. Further, interaction models indicate that SI is significantly higher among those who experience IPV and have either above average levels of postpartum depression or below average levels of self-esteem. This is consistent with a growing body of literature that shows disproportionately elevated perinatal SI among women with comorbid depression (Alhusen, Frohman, \& Purcell, 2015; Bodnar-Deren, Klipstein, Fersh, Shemesh, \& Howell, 2016; Howard, Flach, Mehay, Sharp, \& Tylee, 2011; Jones et al., 2003; Siegel \& Brandon, 2014; Tabb et al., 2013).

Clearly, physical IPV after childbirth leads to a range of risks to the health and wellbeing of the mother, and it is not astounding that it escalates postpartum SI. The contemporaneous impact of experiencing physical and psychological IPV on the maternal mental health is congruent with our expectations. The reason may be that physical IPV following childbirth intensifies their concern for the health and safety of their developing child (Islam, Broidy, Baird, \& Mazerolle, 2017b). Undeniably, past literature associates women's feelings of insufficiency around parenting to postpartum SI (da Cunha Coelho et al., 2014), and physical IPV victimization after childbirth may augment such concerns.

Similar to previous research (Bodnar-Deren, Klipstein, Fersh, Shemesh, \& Howell, 2016; Brausch \& Decker, 2014; Liu \& Mustanski, 2012; Wilson, Droždek, \& Turkovic, 2006), this study revealed that high self-esteem is protective against postpartum SI. We also found a significant interactive effect suggesting that women who have low self-esteem with physical IPV after childbirth are significantly more likely to have postpartum SI compared to women with no physical IPV and low self-esteem. Results underscore the importance of examining protective factors for SI during the perinatal period, as they have the potential to reduce suicide. Surprisingly, and in contrast to the findings of some studies that found social 
support as a protective factor (Brausch \& Decker, 2014; da Cunha Coelho et al., 2014; Peltzer, 2015; Pinheiro et al., 2012), we did not find any contribution of social support on Postpartum SI.

This is the first known study from South Asia that particularly investigated the association of experiencing IPV after childbirth on postpartum SI. One of the strengths of this study is the large sample size, and the introduction of a range of various socio-demographic, reproductive, and psychosocial covariates. Most importantly, the findings of this study are internationally comparable because of the use of internationally recognized measures. Furthermore, the potential recall bias of women in this study is minimized because the mothers were surveyed within six months of the birth. Nevertheless, some limitations should be taken into consideration when interpreting our findings. It is not possible to determine the causal relationship between IPV victimization and postpartum SI due to the cross-sectional nature of this study. To ascertain postpartum SI, a single item from the EPDS was used which may not have captured other significant aspects of SI. We did not focus on the frequency of IPV over time. Furthermore, the survey was conducted in one district only; hence, the findings may not be generalized to the general population. Although a considerable number of covariates were adjusted in this study, some of the important variables were not controlled for, such as shame and prior suicide attempts.

\section{Conclusion}

The excessive prevalence of IPV and postpartum depression, and their associations with postpartum SI demonstrate the significance of acknowledging each of them as an important public health issue in Bangladesh. The results suggest that we cannot simply address IPV among this population, but also need to consider and address its psychological correlates — namely, depression and self-esteem — if we want to reduce the risk of postpartum SI among women. We suggest implementing holistic interventions to prevent or reduce all sorts of IPV, emphasizing the physical and mental health care needs of the victims. The 
results from this study also necessitate considerable attention in the planning of health education programs for health professionals to detect the vulnerability of experiencing IPV and SI. Longitudinal studies exploring the relationship between IPV over the transition to parenthood and postpartum SI are needed to acquire a clear understanding of the association.

\section{Footnote}

1. Among the children, 88 were $1-2$ months old, 168 were $3-4$ months, and 170 children were 5-6 months old.

\section{Competing interests}

The authors declare that they have no competing interests.

\section{Author's contributions}

MJI, LB, PM, KB, and NM planned the study, conceptualized the aim of the study, and finalized the study design. MJI conducted data collection and data analysis, and prepared the manuscript. $\mathrm{LB}, \mathrm{PM}, \mathrm{KB}$, and NM contributed to analysis and interpretation of data and to critical revisions of the article. All authors read the final manuscript and approved it.

\section{Sources of funding}

The study was partially funded by the Joint Donors Technical Assistance Fund (JDTAF) at the Ministry of Health and Family Welfare, Bangladesh. The funding authority had no role in study design, data collection, data analysis, data interpretation, or writing of the manuscript. The corresponding author had full access to all data in the study and had final responsibility for the decision to submit for publication.

\section{Acknowledgments}

We would like to acknowledge all individuals and institutions in Bangladesh involved in the data collection process. We also express our sincere thanks to Dr. Shehlina Ahmed, Health and Population Advisor, DFID Bangladesh, and Md. Helal Uddin, Joint Chief, Ministry of Planning, Bangladesh for providing funding for the study, and for encouraging us to conduct a study on this important issue. 


\section{References:}

Adesina, O., Oyugbo, I., Oladokun, A., \& Olubukola, A. (2011). Prevalence and pattern of violence in pregnancy in Ibadan, South-West Nigeria. Journal of obstetrics and gynaecology, 31(3), 232-236.

Alhusen, J. L., Frohman, N., \& Purcell, G. (2015). Intimate partner violence and suicidal ideation in pregnant women. Arch Womens Ment Health, 18(4), 573578.

Almond, P. (2009). Postnatal depression: A global public health perspective. Perspectives in Public Health, 129(5), 221.

Amiya, R. M., Poudel, K. C., Poudel-Tandukar, K., Pandey, B. D., \& Jimba, M. (2014). Perceived family support, depression, and suicidal ideation among people living with HIV/AIDS: a cross-sectional study in the Kathmandu Valley, Nepal. PLoS One, 9(3), e90959.

Bodnar-Deren, S., Klipstein, K., Fersh, M., Shemesh, E., \& Howell, E. A. (2016). Suicidal ideation during the postpartum period. Journal of Women's Health, 25(12), 1219-1224.

Bondas, T., \& Eriksson, K. (2001). Women's lived experiences of pregnancy: A tapestry of joy and suffering. Qualitative Health Research, 11(6), 824-840.

Bost, K. K., Cox, M. J., Burchinal, M. R., \& Payne, C. (2002). Structural and Supportive Changes in Couples' Family and Friendship Networks across the Transition to Parenthood. Journal of Marriage and Family, 64(2), 517-531.

Brausch, A. M., \& Decker, K. M. (2014). Self-esteem and social support as moderators of depression, body image, and disordered eating for suicidal ideation in adolescents. Journal of abnormal child psychology, 42(5), 779-789. 
Brownridge, D. A., Taillieu, T. L., Tyler, K. A., Tiwari, A., Chan, K. L., \& Santos, S. C. (2011). Pregnancy and intimate partner violence: Risk factors, severity, and health effects. Violence Against Women, 17(7), 858-881.

Cantwell, R., Clutton-Brock, T., Cooper, G., Dawson, A., Drife, J., Garrod, D., Harper, A., Hulbert, D., Lucas, S., McClure, J., Millward-Sadler, H., Neilson, J., Nelson_Piercy, C., Norman, J., O'Herlihy, C., Oates, M., Shakespeare, J., de Swiet, M., Williamson, C., Beale, V., Knight, M., Lennox, C., Miller, A., Parmar, D., Rogers, J., \& Springett, A. (2011). Saving mothers' lives: Reviewing maternal deaths to make motherhood safer: 2006-2008. BJOG: An International Journal of Obstetrics \& Gynaecology, 118(SUPPL. 1), 1-203.

Chan, K. L., Brownridge, D. A., Tiwari, A., Fong, D. Y., Leung, W. C., \& Ho, P. C. (2011). Associating pregnancy with partner violence against Chinese women. $J$ Interpers Violence, 26(7), 1478-1500. doi: 10.1177/0886260510369134

Cox, J. L., Holden, J. M., \& Sagovsky, R. (1987). Detection of postnatal depression. Development of the 10-item Edinburgh Postnatal Depression Scale. the British journal Of psychiatry, 150(6), 782-786. doi: 10.1192/bjp.150.6.782

Czeizel, A. E. (2011). Attempted suicide and pregnancy. Journal of injury and violence research, $3(1), 45-54$.

da Cunha Coelho, F. M., Pinheiro, R. T., Silva, R. A., de Avila Quevedo, L., de Mattos Souza, L. D., de Matos, M. B., Castelli, R. D., \& Pinheiro, K. A. T. (2014). Parental bonding and suicidality in pregnant teenagers: a population-based study in southern Brazil. Social psychiatry and psychiatric epidemiology, 49(8), 12411248.

Deave, T., Johnson, D., \& Ingram, J. (2008). Transition to parenthood: The needs of parents in pregnancy and early parenthood. BMC Pregnancy Childbirth, 8(1), 30-30. doi: 10.1186/1471-2393-8-30 
Devries, K. M., Kishor, S., Johnson, H., Stöckl, H., Bacchus, L. J., Garcia-Moreno, C., \& Watts, C. (2010). Intimate partner violence during pregnancy: analysis of prevalence data from 19 countries. Reproductive Health Matters, 18(36), 158170.

Deyessa, N., Berhane, Y., Alem, A., Ellsberg, M., Emmelin, M., Hogberg, U., \& Kullgren, G. (2009). Intimate partner violence and depression among women in rural Ethiopia: a cross-sectional study. Clinical Practice and Epidemiology in Mental Health, 5(8).

Ellsberg, M., Heise, L., Pena, R., Agurto, S., \& Winkvist, A. (2001). Researching domestic violence against women: methodological and ethical considerations. Stud Fam Plann, 32(1), 1-16.

Fisher, J., Mello, M. C. d., Patel, V., Rahman, A., Tran, T., Holton, S., \& Holmes, W. (2012). Prevalence and determinants of common perinatal mental disorders in women in low-and lower-middle-income countries: a systematic review. Bulletin of the World Health Organization, 90(2), 139-149.

Fonseca-Machado, M. d. O., Alves, L. C., Freitas, P. S., Monteiro, J. C. d. S., \& GomesSponholz, F. (2014). Mental health of women who suffer intimate partner violence during pregnancy. Investigación y Educación en Enfermería, 32(2), 291-305.

Fonseca-Machado, M. d. O., Alves, L. C., Haas, V. J., Monteiro, J. C. D., \& GomesSponholz, F. (2015). Under the shadow of maternity: pregnancy, suicidal ideation, and intimate partner violence. REVISTA PANAMERICANA DE SALUD PUBLICA-PAN AMERICAN JOURNAL OF PUBLIC HEALTH, 37(4-5), 258264.

Garcia-Moreno, C., Jansen, H. A. F. M., Ellsberg, M., Heise, L., \& Watts, C. H. (2005). WHO multi-country study on women's health and domestic violence against 
women: Initial results on prevalence, health outcomes and women's responses. Geneva: World Health Organization.

Garcia-Moreno, C., Jansen, H. A. F. M., Ellsberg, M., Heise, L., \& Watts, C. H. (2006). Prevalence of intimate partner violence: findings from the WHO multi-country study on women's health and domestic violence. The Lancet, 368, 1260-1269.

Gausia, K., Fisher, C., Algin, S., \& Oosthuizen, J. (2007). Validation of the Bangla version of the Edinburgh Postnatal Depression Scale for a Bangladeshi sample. JOURNAL OF REPRODUCTIVE AND INFANT PSYCHOLOGY, 25(4), 308315. doi: $10.1080 / 02646830701644896$

Gausia, K., Fisher, C., Ali, M., \& Oosthuizen, J. (2008). Magnitude and contributory factors of postnatal depression: a community-based cohort study from a rural subdistrict of Bangladesh. Psychological medicine, 39(6), 999-1007.

Gausia, K., Fisher, C., Ali, M., \& Oosthuizen, J. (2009). Antenatal depression and suicidal ideation among rural Bangladeshi women: a community-based study. Arch Womens Ment Health, 12(5), 351-358.

Gavin, A. R., Tabb, K. M., Melville, J. L., Guo, Y., \& Katon, W. (2011). Prevalence and correlates of suicidal ideation during pregnancy. Arch Womens Ment Health, 14(3), 239-246.

Gelaye, B., Kajeepeta, S., \& Williams, M. A. (2016). Suicidal ideation in pregnancy: an epidemiologic review. Arch Womens Ment Health, 19(5), 741-751.

Gold, K. J., Singh, V., Marcus, S. M., \& Palladino, C. L. (2012). Mental health, substance use and intimate partner problems among pregnant and postpartum suicide victims in the National Violent Death Reporting System. General hospital psychiatry, 34(2), 139-145.

Gulliver, P., \& Fanslow, J. (2013). Exploring risk factors for suicidal ideation in a population-based sample of New Zealand women who have experienced 
intimate partner violence. Australian and New Zealand Journal of Public Health, 37(6), 527-533.

Howard, L. M., Flach, C., Mehay, A., Sharp, D., \& Tylee, A. (2011). The prevalence of suicidal ideation identified by the Edinburgh Postnatal Depression Scale in postpartum women in primary care: findings from the RESPOND trial. $B M C$ Pregnancy Childbirth, 11(1), 57-57.

Howard, L. M., Oram, S., Galley, H., Trevillion, K., \& Feder, G. (2013). Domestic violence and perinatal mental disorders: a systematic review and meta-analysis. PLoS medicine, 10(5), e1001452.

Islam, M. J., Baird, K., Mazerolle, P., \& Broidy, L. (2017). Exploring the influence of psychosocial factors on exclusive breastfeeding in Bangladesh. Archives of Women's Mental Health, 20(1), 173-188. doi: 10.1007/s00737-016-0692-7

Islam, M. J., Broidy, L., Baird, K., \& Mazerolle, P. (2017a). Exploring the associations between intimate partner violence and delayed entry to prenatal care: Evidence from a cross-sectional study in Bangladesh. Midwifery, 47, 43-55. doi: 10.1016/j.midw.2017.02.002

Islam, M. J., Broidy, L., Baird, K., \& Mazerolle, P. (2017b). Intimate partner violence around the time of pregnancy and postpartum depression: The experience of women of Bangladesh. PLoS One, 12(5), e017621. doi: 10.1371/journal.pone.0176211

Islam, M. J., Mazerolle, P., Broidy, L., \& Baird, K. (2017). Exploring the prevalence and correlates associated with intimate partner violence during pregnancy in Bangladesh. J Interpers Violence. doi: 10.1177/0886260517730029

Isomaa, R., Vaananen, J.-M., Forojd, S., Kaltiala-Heino, R., \& Marttunen, M. (2013). How low is low? Low self-esteem as an indicator of internalizing psychopathology in adolescence. Health Education \& Behavior, 40(4), 392-399. 
James, L., Brody, D., \& Hamilton, Z. (2013). Risk factors for domestic violence during pregnancy: a meta-analytic review. Violence and victims, 28(3), 359-380.

Joiner, T. E. (2005). Why people die by suicide. Cambridge, MA: Harvard University Press.

Jones, J. E., Hermann, B. P., Barry, J. J., Gilliam, F. G., Kanner, A. M., \& Meador, K. J. (2003). Rates and risk factors for suicide, suicidal ideation, and suicide attempts in chronic epilepsy. Epilepsy \& Behavior, 4, 31-38.

Kantor, G. K., \& Straus, M. A. (1999). Report on the USAF Family Needs Screener. Durham, NH: Family Research Laboratory.

Kim, J. J., Silver, R. K., La Porte, L. M., Zhou, Y., Allweiss, S. B., \& Adams, M. G. (2014). Clinical correlates of maternal suicidal ideation detected by perinatal depression screening. Obstetrics \& Gynecology, 123, 60S.

Leiner, A. S., Compton, M. T., Houry, D., \& Kaslow, N. J. (2008). Intimate partner violence, psychological distress, and suicidality: A path model using data from African American women seeking care in an Urban Emergency Department. Journal of family violence, 23(6), 473-481.

Leung, S. S. K., Martinson, I. M., \& Arthur, D. (2005). Postpartum depression and related psychosocial variables in Hong Kong Chinese women: findings from a prospective study. Research in nursing \& health, 28(1), 27-38.

Lindahl, V., Pearson, J. L., \& Colpe, L. (2005). Prevalence of suicidality during pregnancy and the postpartum. Arch Womens Ment Health, 8(2), 77-87. doi: $10.1007 / \mathrm{s} 00737-005-0080-1$

Liu, R. T., \& Mustanski, B. (2012). Suicidal ideation and self-harm in lesbian, gay, bisexual, and transgender youth. American journal of preventive medicine, 42(3), 221-228. 
Loft Abadi, M. N., Ghazinour, M., Nojomi, M., \& Richter, J. (2012). The buffering effect of social support between domestic violence and self-esteem in pregnant women in Tehran, Iran. Journal of family violence, 27(3), 225-231.

Martin, S. L., Harris-Britt, A., Li, Y., Moracco, K. E., Kupper, L. L., \& Campbell, J. C. (2004). Changes in intimate partner violence during pregnancy. Journal of family violence, 19(4), 201-210.

Mauri, M., Oppo, A., Borri, C., \& Banti, S. (2012). Suicidality in the perinatal period: comparison of two self-report instruments. Results from PND-ReScU. Arch Womens Ment Health, 15(1), 39-47.

McLaughlin, J., O'Carroll, R. E., \& O'Connor, R. C. (2012). Intimate partner abuse and suicidality: A systematic review. Clinical psychology review, 32(8), 677-689.

Mohammadhosseini, E., Sahraean, L., \& Bahrami, T. (2010). Domestic abuse before, during and after pregnancy in Jahrom, Islamic Republic of Iran. Eastern Mediterranean Health Journal, 16(7), 752-758.

Muzik, M., Brier, Z., Menke, R. A., Davis, M. T., \& Sexton, M. B. (2016). Longitudinal suicidal ideation across 18 -months postpartum in mothers with childhood maltreatment histories. Journal of affective disorders, 204, 138-145.

Naved, R. T., \& Akhtar, N. (2008). Spousal violence against women and suicidal ideation in Bangladesh. Women's health issues, 18(6), 442-452.

Newport, D. J., Levey, L. C., Pennell, P. B., Ragan, K., \& Stowe, Z. N. (2007). Suicidal ideation in pregnancy: assessment and clinical implications. Arch Womens Ment Health, 10(5), 181-187.

Oates, M. (2003). Perinatal psychiatric disorders: a leading cause of maternal morbidity and mortality. British medical bulletin, 67(1), 219-229. 
Onah, M. N., Field, S., Bantjes, J., \& Honikman, S. (2017). Perinatal suicidal ideation and behaviour: psychiatry and adversity. Arch Womens Ment Health, 20(2), 321331.

Palladino, C. L., Singh, V., Campbell, J., Flynn, H., \& Gold, K. (2011). Homicide and suicide during the perinatal period: findings from the National Violent Death Reporting System. Obstetrics and gynecology, 118(5), 1056-1063.

Peltzer, K. (2015). Prevalence of suicidal ideation and associated factors among postpartum HIV-positive women in health facilities, South Africa. Journal of Psychology in Africa, 25(6), 547-550.

Pico-Alfonso, M. A., Garcia-Linares, M. I., Celda-Navarro, N., Blasco-Ros, C., Echeburúa, E., \& Martinez, M. (2006). The impact of physical, psychological, and sexual intimate male partner violence on women's mental health: depressive symptoms, posttraumatic stress disorder, state anxiety, and suicide. Journal of Women's Health, 15(5), 599-611.

Pinheiro, R. T., da Cunha Coelho, F. M., da Silva, R. A., de Ávila Quevedo, L., de Mattos Souza, L. D., Castelli, R. D., de Matos, M. B., \& Pinheiro, K. A. T. (2012). Suicidal behavior in pregnant teenagers in southern Brazil: social, obstetric and psychiatric correlates. Journal of affective disorders, 136(3), 520525.

Ribeiro, J. D., \& Joiner, T. E. (2011). Present status and future prospects take up the interpersonal-psychological theory of suicidal behaviour. In R. C. O'Connor, S. Platt \& J. Gordon (Eds.), International handbook of suicide prevention: Research, Policy and Practice (pp. 169-179). UK: Wiley-Blackwell.

Rochat, T. J., Bland, R. M., Tomlinson, M., \& Stein, A. (2013). Suicide ideation, depression and HIV among pregnant women in rural South Africa. Health, 5(3A), 650-661. 
Rodríguez, M. A., Valentine, J., Ahmed, S. R., Eisenman, D. P., Sumner, L. A., Heilemann, M. V., \& Liu, H. (2010). Intimate Partner Violence and Maternal Depression During the Perinatal Period: A Longitudinal Investigation of Latinas. Violence Against Women, 16(5), 543-559.

Rodriguez, V. J., Cook, R. R., Peltzer, K., \& Jones, D. L. (2017). Prevalence and psychosocial correlates of suicidal ideation among pregnant women living with HIV in Mpumalanga Province, South Africa. AIDS Care, 29(5), 593-597.

Rosenberg, M. (1965). Society and the adolescent self-image. Princeton, N.J Princeton University Press.

Saito, A., Creedy, D., Cooke, M., \& Chaboyer, W. (2012). Effect of intimate partner violence on postpartum women's health in northeastern Thailand. Nursing \& health sciences, 14(3), 345-351.

Shamu, S., Zarowsky, C., Roelens, K., Temmerman, M., \& Abrahams, N. (2016). Highfrequency intimate partner violence during pregnancy, postnatal depression and suicidal tendencies in Harare, Zimbabwe. General hospital psychiatry, 38, 109114.

Sharaf, A. Y., Thompson, E. A., \& Walsh, E. (2009). Protective effects of self-esteem and family support on suicide risk behaviors among at-risk adolescents. Journal of Child and Adolescent Psychiatric Nursing, 22(3), 160-168.

Siegel, R. S., \& Brandon, A. R. (2014). Adolescents, pregnancy, and mental health. Journal of pediatric and adolescent gynecology, 27(3), 138-150.

Sit, D., Luther, J., Buysse, D., Dills, J. L., Eng, H., Okun, M., Wisniewski, S., \& Wisner, K. L. (2015). Suicidal ideation in depressed postpartum women: associations with childhood trauma, sleep disturbance and anxiety. Journal of psychiatric research, 66, 95-104. 
Tabb, K. M., Gavin, A. R., Guo, Y., Huang, H., Debiec, K., \& Katon, W. (2013). Views and experiences of suicidal ideation during pregnancy and the postpartum: Findings from interviews with maternal care clinic patients. Women and Health, $53(5)$.

Tabb, K. M., Huang, H., Valdovinos, M., Toor, R., Ostler, T., Vanderwater, E., Wang, Y., Menezes, P. R., \& Faisal-Cury, A. (2017). Intimate partner violence is associated with suicidality among low-income postpartum women. Journal of Women's Health.

The Participation and Quality of Life Tool-Kit. (2016). Rosenberg Self-Esteem Scale. Retrieved 12 December, 2016, from http://www.parqol.com/page.cfm?id=142

Tsai, A. C., Tomlinson, M., Comulada, W. S., \& Rotheram-Borus, M. J. (2016). Intimate Partner Violence and Depression Symptom Severity among South African Women during Pregnancy and Postpartum: Population-Based Prospective Cohort Study. PLoS medicine, 13(1), e1001943.

Uddin, M. K., Islam, M. T., \& Asaduzzaman, M. (2012). Perceived Stress and SelfEsteem as Significant Predictors of Cigarette Smoking Behavior of Bangladeshi Male Adults. Journal of Behavioural Sciences, 22(2), 26-38.

United Nations Secretary-General. (2015). The Global Strategy for Women's, Children's and Adolescents' Health, 2016-2030. New York: United Nations.

W.W. Norton and Company. (2016). Rosenberg Self-Esteem Scale. Retrieved 12 December, 2016, from http://www.wwnorton.com/college/psych/psychsci/media/rosenberg.htm

Wang, S.-Y., \& Chen, C.-H. (2006). Psychosocial health of Taiwanese postnatal husbands and wives. Journal of psychosomatic research, 60(3), 303-307. 
Wang, S.-Y., Jiang, X.-Y., Jan, W.-C., \& Chen, C.-H. (2003). A comparative study of postnatal depression and its predictors in Taiwan and mainland China. American journal of obstetrics and gynecology, 189(5), 1407-1412.

WHO. (2014). Trends in maternal mortality: 1990 to 2013. Geneva: WHO, UNICEF, UNFPA, The World Bank and the United Nations Population Division.

Wilson, J. P., Droždek, B., \& Turkovic, S. (2006). Posttraumatic shame and guilt. TRAUMA, VIOLENCE, \& ABUSE, 7(2), 122-141.

Woolhouse, H., Gartland, D., Hegarty, K., Donath, S., \& Brown, S. J. (2012).

Depressive symptoms and intimate partner violence in the 12 months after childbirth: a prospective pregnancy cohort study. BJOG, 119(3), 315-323.

World Health Organization. (2013). Global and regional estimates of violence against women: prevalence and health effects of intimate partner violence and nonpartner sexual violence. Geneva, Switzerland: World Health Organization.

World Health Organization. (2014). Preventing suicide: a global imperative: World Health Organization. 